\title{
PERCEPÇÃo e ESTRATÉgIAS de EQUIPES PedAgógICAS eM RELAÇÃo Ao LUTO DE ALUNOS DOS ANOS INICIAIS
}

\begin{tabular}{c}
\hline PERCEPTION AND STRATEGIES OF EDUCATIONAL TEAMS IN RELATION TO THE \\
MOURNIG OF STUDENTS IN THE EARLY YEARS \\
\hline PERCEPCIÓN Y ESTRATEGIAS DE EQUIPOS PEDAGÓGICOS EN RELACIÓN AL \\
DUELO DE ALUMNOS DE LOS AÑOS INICIALES
\end{tabular}

\author{
Maiara Cardoso dos Santos Souza ${ }^{\mathrm{i}}$ \\ Renata Lissa Zwolinski $i^{\mathrm{ii}}$ \\ Rosina Forteski Glidden ${ }^{\text {iii }}$
}

\begin{abstract}
RESUMO: Morrer é um acontecimento natural diante do qual as crianças podem vivenciar o luto e demandar da equipe pedagógica suporte e intervenção. Essa pesquisa teve por objetivo analisar a percepção de equipes pedagógicas sobre o luto de alunos dos anos iniciais, sobre as possibilidades de acolhimento e intervenção frente a essa demanda e possíveis relações com a vivência de luto dos próprios profissionais. Participaram 33 profissionais de duas escolas de Santa Catarina. Foi aplicado um questionário semiestruturado e a análise dos dados foi feita com estatística não paramétrica e análise semântica das perguntas abertas. Os resultados mostraram que os participantes consideram importante trabalhar o tema luto com os alunos para prepará-los para vivenciar a morte de um ente querido.
\end{abstract}

PALAVRAS-CHAVE: Educação. Luto infantil. Luto na escola.

ABSTRACT: Dying is a natural event in which children can experience grief and demand pedagogical support and intervention. This research aimed to analyze the perception of school pedagogical staffs about the grief of elementary school students, the possibilities of support and intervention in face of this demand, and possible relations with the experience of grief of the professionals in their own lives. Thirty-three school professionals from two schools in Santa Catarina participated in this study. A semi-structured questionnaire was applied, and for the data analysis, non-parametric statistics and semantic analysis of the open questions were used. The results showed that the participants consider it important to work on the grief theme with students to prepare them for the experience the death of an loved one.

KEYWORDS: Education. Children's grief. Grief at school.

RESUMÉN: Morir es un acontecimiento natural ante el cual los niños pueden experimentar el duelo y demandar del equipo pedagógico apoyo e intervención. Esta investigación tuvo por objetivo analizar la percepción de equipos pedagógicos sobre el duelo de alumnos de los años iniciales, sobre las posibilidades de acogida e intervención frente a esa demanda y posibles relaciones con la vivencia del duelo de los propios profesionales. Participaron 33 profesionales de dos escuelas de Santa Catarina. Se aplicó un cuestionario semiestructurado y el análisis de los datos se hizo con estadística no paramétrica y análisis semántico de las preguntas abiertas. Los resultados mostraron que los participantes consideran importante trabajar el tema duelo con los alumnos para prepararlos para vivir la muerte de un ser querido.

PALABRAS CLAVE: Educación. Duelo infantil. Duelo en la escuela.

Submetido em: 31/01/2017 - Aceito em: 26/04/2017 - Publicado em: 22/09/2017.

\begin{tabular}{l|l|l|l|l|l|l} 
(C) Rev. Educ. Perspec. & Viçosa, $M G$ & v.6 & n.2 & p.177-197 & maio/ago. 2017 & eISSN 2178-8359 \\
\hline
\end{tabular}




\section{INTRODUÇÃO}

O significado que a criança dá à morte terá variações e dependerá de alguns fatores. O primeiro a ser considerado é o seu momento de desenvolvimento. A vinculação afetiva que ela estabelece com as pessoas gera a consciência de que existe a possibilidade de perder essa pessoa. $\mathrm{O}$ medo da morte é motivado pelo medo de perder o ente querido e assim romper vínculos (BROMBERG, 1998). Subsequente à perda, vem o período do luto que, do ponto de vista de Mazorra e Tinoco (2005), tem como objetivo a adaptação emocional do indivíduo acerca da perda, é o momento em que a criança irá reconstruir-se e reorganizar-se, esse é um desafio emocional e cognitivo com o qual ela tem que lidar.

A escola deve estar sempre atenta para não ignorar o aluno que está em luto de morte e não dissimular como se nada tivesse acontecido. Segundo a autora, se faz necessário deixar um espaço para a comunicação, respeitando as várias manifestações infantis acerca do assunto (KOVÁCS, 2012). No ambiente escolar são discutidas muitas questões corriqueiras relacionadas à sociedade, muitas experiências pessoais são vividas neste espaço durante a preparação para a vida social. Assim, esse também poderia ser um ambiente propício para abordar e refletir sobre o assunto morte (KOVÁCS, 2012; PAIVA, 2011).

Daí a necessidade em se efetivar uma atuação preventiva para lidar com o luto com as crianças, seja no momento do evento ou quando ela ainda não se concretizou. Diante do exposto, esse trabalho teve por objetivo analisar a percepção de equipes pedagógicas sobre o luto de alunos de anos iniciais, sobre as possibilidades de acolhimento e intervenção desses profissionais frente a essa demanda e possíveis relações com a vivência de luto dos próprios profissionais em suas vidas.

\section{REVISÃO DE LITERATURA}

O morrer perante a sociedade carrega um papel expressivo, a postura diante da morte e da pessoa que morreu tem um papel decisivo na constituição e formulação da identidade da pessoa em luto e, em consequência, na formação de uma tradição cultural comum (GIACOIA, 2005). Do ponto de vista de Kappel (2013), durante o processo de luto a pessoa passará por diversas fases até atingir o reequilíbrio e buscar um novo recomeço para a sua vida. Nesse sentido, Jaramillo (2006) acrescenta que o luto é uma superação que acontece, de forma pessoal e individual, até o ponto em que ocorre a reacomodação da vida de uma forma nova, se readaptando à perda. 


\section{Luto: A Vivência do Adulto}

Quando acontece a perda de algo no que foi investido valores afetivos, as várias reações que surgem em consequência desse evento são consideradas luto (FUJISAKA, KOVÁCS, 2011). Segundo as autoras, isso ocorre em função da quebra de vínculo, que exige do indivíduo uma reorganização gradual da vida e uma redefinição de papeis, relações e atividades.

A elaboração do luto e sua superação passa por várias fases, primeiramente de forma individual e posteriormente como um conjunto de condutas, ao final a pessoa pode retomar a sua vida, considerando algumas reorganizações (TORRES, 2009). Moura (2006) acrescenta que quando a perda é referente à morte, ela é vista como grande e extrema. Grande em relação às várias outras perdas relacionais e extrema por não haver a possibilidade de recuperar aquele que já morreu.

Chegar ao fim e conseguir elaborar o luto não significa esquecer quem se perdeu e que foi importante, mas sim voltar à vida normal após a perda. Assim, sentir saudades e a ausência daquele que não mais se faz presente continuará fazendo parte das vivências da pessoa, mas agora de uma maneira na qual ela aprende a conviver com a perda e pode retomar a sua vida (TORRES, 2009).

\section{Luto: A Vivência Infantil}

A morte faz parte do desenvolvimento humano, mas muitas pessoas ainda acreditam que as crianças são muito vulneráveis para passar pelo sofrimento da perda, por esse motivo, normalmente a morte de um ente querido é mantida em segredo (SILVA, WENDLING, 2010; TADA, KOVÁCS, 2007). O luto é um processo no qual a criança reconstrói e reorganiza sua vida de acordo com as consequências que a vivência da morte lhe trouxe, é um desafio emocional com o qual ela tem que lidar (FRANCO, MAZORRA, 2007).

Como a criança ainda depende da família para auxiliá-la no processo de luto, o rompimento que acontece no momento da perda exige uma reorganização emocional da família para que a criança também possa se reestruturar. A criança, quando assimila a perda, percebe a nova realidade, e é nessa hora que é preciso conversar e esclarecer dúvidas sobre essa perda. Esse momento de confiança que se estabelece ao conversar com a criança é importante para que ela consiga concretizar o luto de uma forma saudável (ANTON, FAVERO, 2011).

A importância de dialogar com a criança sobre o luto é relatada por Kappel (2013), em sua pesquisa realizada com a finalidade de investigar as consequências do luto infantil por meio das representações sobre o luto de 25 crianças, entre nove e 13 anos de idade, de uma escola pública. Os resultados da pesquisa apontaram que "se a criança não recebe informações sobre o

\begin{tabular}{l|l|l|l|l|l|l} 
() Rev. Educ. Perspec. & Viçosa, $M G$ & v.6 & n.2 & p.177-197 & maio/ago. 2017 & eISSN 2178-8359 \\
\hline
\end{tabular}


processo de luto, dificilmente ela terá como falar e argumentar sobre o que está sentindo" (KAPPEL, 2013, p. 47). Ao fim da pesquisa a autora observou que, mesmo a morte sendo uma etapa natural da vida, muitas das crianças mostraram-se confusas e despreparadas para assimilar situações ligadas a este evento, pela falta de informação em relação ao assunto.

\section{Luto Infantil na Escola}

No âmbito escolar os alunos estão sempre atentos às palavras e ações de seus educadores, o que remete à reflexão sobre como o educador tem influência sobre seus alunos. Isso pode ser usado para favorecer a comunicação entre aluno e professor e abrir espaço para sentimentos e emoções quando o aluno estiver passando por um processo de luto. Para tanto, é importante que os professores busquem compreender o luto da criança e entrem em contato com a visão que eles mesmos têm sobre a morte (KOVÁCS, 2012).

No estudo realizado por Kovács (2012) com professores de escolas participantes do Programa Amigos do Zippy, alguns participantes afirmaram que, para abordar o tema luto com os alunos, é preciso que eles próprios tenham uma organização do conhecimento sobre o tema e que a experiência individual é de grande relevância neste processo. Essa preparação é muito importante no momento de conversar com as crianças sobre luto, pois é preciso que os profissionais tenham muito cuidado ao falar com a criança sobre a morte. Cumpre que os profissionais levem sempre em conta a delicadeza desse assunto para a criança, as indagações que o cercam e os sentimentos que ela percebe em si mesma nesse momento.

\section{MÉTODO}

Esse estudo caracteriza-se como uma pesquisa exploratória, não experimental, com objetivos descritivos e de delineamento misto. Sobre a opção por métodos mistos nas pesquisas em educação, Dal-Farra e Lopes (2013) pontuam que o uso de abordagens diversificadas para acessar o fenômeno investigado permite contribuições mútuas a respeito dos potenciais de cada uma. Assim, resultados mais abrangentes podem ser alcançados.

Os participantes desta pesquisa constituíram uma amostra de conveniência. Neste tipo de amostra os participantes são selecionados pelo critério de acessibilidade, dando-se preferência aos que estão no contexto a ser investigado e que têm possibilidades de responder sobre o tema pesquisado (RUIZ-OLABUENÁGA, 2012).

A análise dos dados foi feita por meio de porcentagens, frequências simples e estatística não paramétrica (Qui-quadrado), indicada para pequenas amostras, como é o caso do presente estudo. A estatística não paramétrica é uma opção também para pesquisas cujos dados obtidos

\begin{tabular}{l|l|l|l|l|l|l} 
() Rev. Educ. Perspec. & Viçosa, $M G$ & v.6 & n.2 & p.177-197 & maio/ago. 2017 & eISSN 2178-8359 \\
\hline
\end{tabular}


não tenham uma distribuição simétrica. O Qui-quadrado permite a investigação de variáveis nominais expressas em termos de taxas, frequências e proporções (CADDIS, CADDIS, 1990). As respostas às perguntas abertas passaram por análise semântica, dos relatos emergiram categorias de análise qualitativa que foram discutidas em relação aos dados demográficos e também à luz da literatura da área.

\section{Participantes e Local}

Participaram da pesquisa 33 profissionais da equipe pedagógica de duas escolas, uma pública e uma particular, de um município do Norte de Santa Catarina. Foram considerados profissionais da equipe pedagógica o(a) diretor(a), orientador(a), psicólogo(a), auxiliares de sala e professores(as) dos anos iniciais. O parâmetro de seleção desses profissionais foi atuar de algum modo com alunos dos anos iniciais e pertencer às escolas selecionadas. Os profissionais foram convidados a participar da pesquisa individualmente, após lhe serem fornecidos os devidos esclarecimentos acerca da natureza e dos objetivos do estudo e da sua assinatura no Termo de Consentimento Livre e Esclarecido. A pesquisa foi submetida ao Comitê de Ética Fameblu/Uniasselvi, obtendo aprovação sob o número 285/2015.

\section{Procedimentos para Coleta de Dados}

A coleta de dados na escola pública aconteceu na cantina. Porém, em horário de aula não havia circulação de alunos. $\mathrm{Na}$ escola particular a coleta ocorreu na biblioteca. Assim, ambos os locais dispuseram de um espaço adequado para que os participantes pudessem se acomodar para responder ao questionário. Havia pouca possibilidade de interrupção e barulho devido aos horários de aplicação, estando as pesquisadoras presentes para sanar eventuais dúvidas. A aplicação do instrumento foi individual.

\section{RESULTADOS E DISCUSSÃO}

Esta pesquisa foi realizada em duas escolas, sendo uma da rede do ensino público e uma da rede privada, ambas de uma cidade do Norte do estado de SC. Participaram profissionais ( $\mathrm{n}=$ 33) de suas equipes pedagógicas, sendo 60,6\% da escola privada e 39,4\% da escola pública. Desses profissionais, $51,5 \%$ eram professores, $33,3 \%$ auxiliares de sala, $9,1 \%$ coordenadores(as) pedagógicos(as) e 6,1\% diretores(as). Todos os professores atuavam como regentes. A idade média dos participantes foi de 31,6 anos com desvio padrão de 9,95. Quando considerados só os professores $(\mathrm{n}=17)$, a média de idade encontrada foi de 35,6 anos com desvio padrão de 8,70 . As auxiliares de sala $(n=11)$, todas mulheres, apresentaram média de idade menor $(22,2$ anos com desvio padrão de 4,70$)$ e todas trabalhavam na escola particular.

\begin{tabular}{l|c|c|c|c|c|c} 
() Rev. Educ. Perspec. & Viçosa, $M G$ & v.6 & n.2 & p.177-197 & maio/ago. 2017 & eISSN 2178-8359 \\
\hline
\end{tabular}


As variáveis idade dos profissionais e tipo de escola em que trabalham obtiveram relação significativa $\left(\chi^{2}=8,17 ; p<0,05\right)$. Dos profissionais da escola pública, 75,0\% tinham idade de 30 a 45 anos, enquanto na escola privada $35,0 \%$ estavam nessa faixa, concentrando sua maior porcentagem (60\%) nos profissionais com até 29 anos. Assim, na escola privada encontravamse os profissionais mais jovens.

Outra relação que teve resultado significativo $\left(\chi^{2}=14,57 ; p<0,05\right)$ está relacionada ao tempo que os professores trabalham na função em cada escola. Dos profissionais que trabalham entre onze e 15 anos na função, obteve-se 30,8\% na escola pública e $12,5 \%$ na privada. Com 20 anos ou mais na escola pública somam $46,2 \%$ enquanto na privada não havia professores com esse tempo de trabalho. Nota-se então, que os professores com mais tempo de profissão estavam na escola pública.

O tipo de escola apresentou relação significativa $\left(\chi^{2}=14,57 ; p<0,05\right)$ com o nível educacional dos profissionais. O maior nível de formação acadêmica na escola pública foi Especialização $(76,9 \%)$ e na escola privada a Graduação $(61,1 \%)$. Percebe-se assim, que maiores níveis de formação foram encontrados na escola pública.

Os três resultados citados anteriormente se justificam pela presença das auxiliares de sala na escola particular, que representam a parte mais jovem da amostra, portanto em início de suas carreiras e com menores níveis de formação profissional.

\section{Percepção sobre trabalhar o Tema Morte com os Alunos}

Os profissionais participantes da pesquisa foram questionados sobre a possibilidade de trabalhar o tema morte com os alunos em sala. A variável tipo de escola obteve relação significativa $\left(\chi^{2}=4,39 ; p<0,05\right)$ com o relato dos profissionais sobre ter ou não pensado na possibilidade de trabalhar a morte com seus alunos, como pode-se observar na Figura 1:

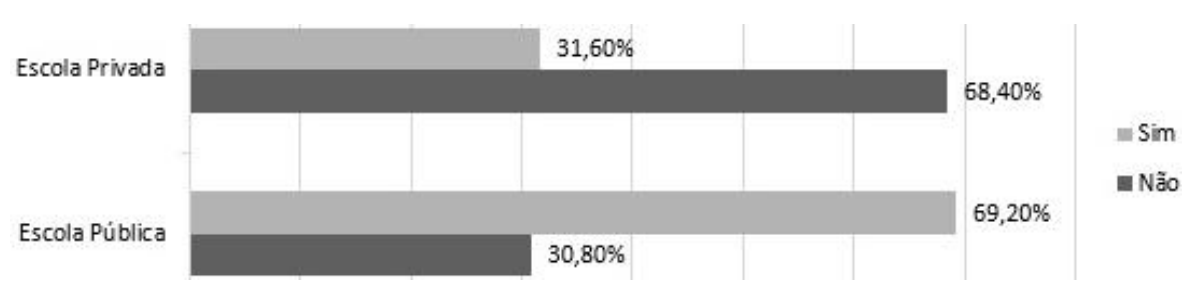

Figura 1. Relação entre o tipo de escola e se o profissional pensou ou não na possibilidade de trabalhar o tema morte com os alunos em sala $\left(\chi^{2}=4,39 ; \mathrm{p}<0,05\right)$

Fonte: Dados da própria pesquisa.

\begin{tabular}{l|c|c|c|c|c|c} 
() Rev. Educ. Perspec. & Viçosa, $M G$ & v.6 & n.2 & p.177-197 & maio/ago. 2017 & eISSN 2178-8359 \\
\hline
\end{tabular}


De acordo com os dados apresentados na Figura 1, é possível perceber uma diferença de opiniões entre os profissionais das duas escolas. Dos profissionais que disseram ter pensado na possibilidade de trabalhar a morte em sala, 69,2\% são da escola pública e 31,6\% da privada. Obtendo-se assim o dado de que na escola pública encontra-se a maioria dos profissionais que já pensaram nesta possibilidade.

Considerando os cargos e se os profissionais pensaram na possibilidade de trabalhar a morte com os alunos em sala ou não, percebeu-se no cargo de auxiliar de sala $80 \%$ das participantes relataram que não pensaram em trabalhar com os alunos o tema. Com as diretoras, ambas relatam o mesmo posicionamento. Nos professores, 55,6\% relataram que já pensaram na possibilidade de trabalhar o tema morte com os alunos, assim como todos os coordenadores pedagógicos.

Ter ou não filhos encontrou relação significativa $\left(\chi^{2}=4,22 ; \mathrm{p}<0,05\right)$ com a variável se o profissional pensou na possibilidade de trabalhar o tema morte com os alunos em sala, como se pode observar na Figura 2:

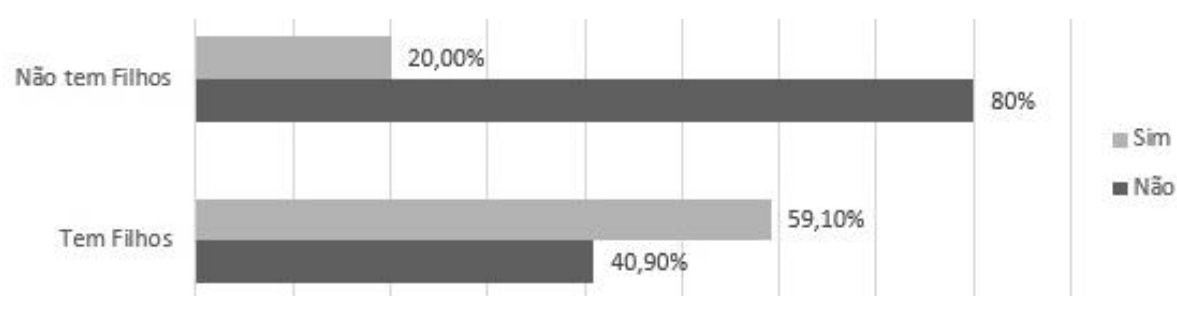

Figura 2. Relação entre ter ou não filhos e ter pensado na possibilidade de trabalhar o luto em sala com os alunos $\left(\chi^{2}=4,22 ; p<0,05\right)$

Fonte: Dados da própria pesquisa.

Segundo os dados da Figura 2 pode-se observar que, dos profissionais que não têm filhos, 80,0\% relataram não ter pensado na possibilidade de trabalhar o luto com os alunos. Já nos profissionais que têm filhos, a maioria $(59,1 \%)$ relatou já ter pensado nesta possibilidade. Com isso, observa-se que os profissionais que têm filhos tendem a pensar mais sobre abordar o tema em classe.

\section{Ocorrência de Aluno em Luto durante a Atuação do Profissional}

A variável tipo de escola obteve relação significativa $\left(\chi^{2}=7,62 ; p<0,05\right)$ com a ocorrência de luto de aluno, como pode-se observar na Figura 3: 


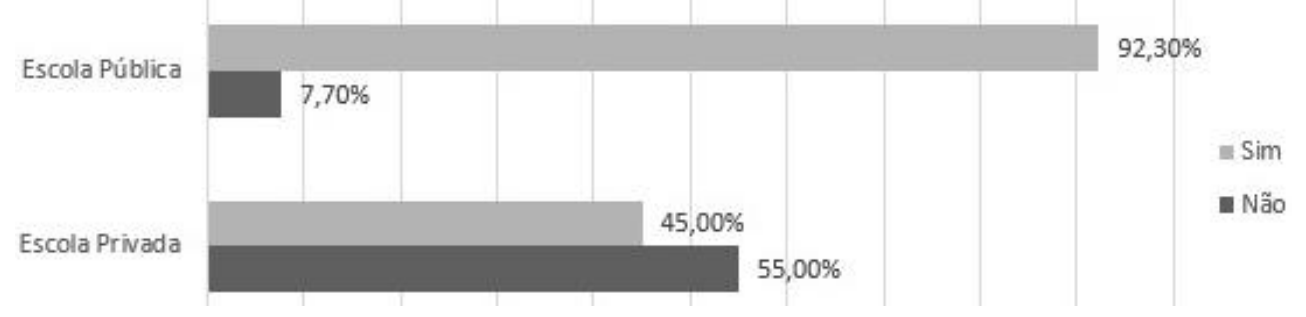

Figura 3. Relação entre tipo de escola e se houve ou não algum aluno em luto durante sua atuação do profissional $\left(\chi^{2}=7,62 ; \mathrm{p}<0,05\right)$

Fonte: Dados da própria pesquisa.

A maioria $(92,3 \%)$ dos profissionais da escola pública relatou a ocorrência de um aluno em luto, enquanto que na escola privada somente $45,0 \%$ relataram essa ocorrência. Com esses dados, observa-se que os profissionais da escola pública, que estão em uma faixa etária mais alta e têm mais tempo de atuação na área, têm uma experiência maior com a ocorrência de alunos enlutados.

A Figura 4 traz a distribuição por cargo sobre o relato dos participantes de terem vivenciado a ocorrência de luto de um aluno ou não.

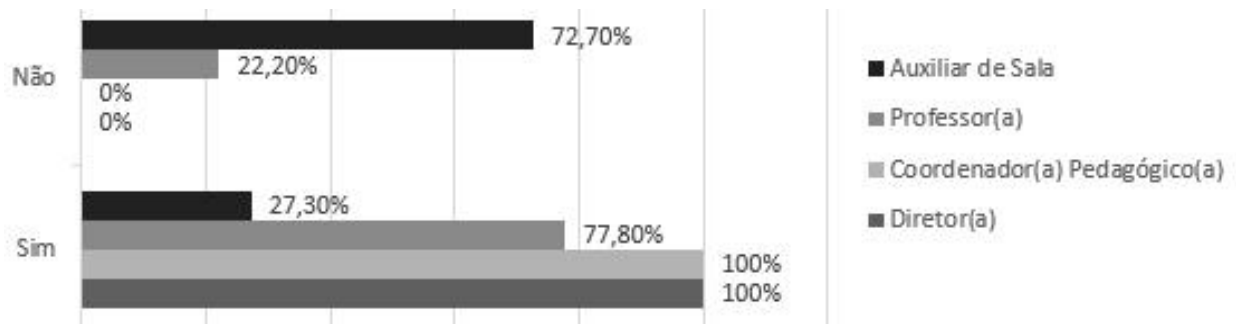

Figura 4. Relação entre cargo dos participantes e se houve ou não algum aluno em luto durante sua atuação profissional

Fonte: Dados da própria pesquisa.

De acordo com os dados da Figura 4, 77,8\% dos professores afirmaram terem tido a experiência de trabalhar com algum aluno em luto e das auxiliares $27,3 \%$ fizeram este relato. Assim, as profissionais que atuam como auxiliares de sala são as que menos viveram esta experiência, sugere-se a hipótese deste resultado ter relação com seu pouco tempo de atuação.

\section{Possíveis Estratégias Preestabelecidas pelas Escolas para trabalhar o Luto com os Alunos}

No total da amostra, em relação a ter ou não estratégias que abordem o luto com as crianças em suas escolas, 76,0\% disseram dos participantes relataram que não e de $24,0 \%$ que sim. Distinguindo os resultados por escola, tem-se na pública $66,7 \%$ de participantes relatando que

\begin{tabular}{l|c|c|c|c|c|c} 
() Rev. Educ. Perspec. & Viçosa, $M G$ & v.6 & n.2 & p.177-197 & maio/ago. 2017 & eISSN 2178-8359 \\
\hline
\end{tabular}


sua escola não possuía tais estratégias, e na privada também a maioria $(81,2 \%)$ traz o dado de que sua escola não possuía essas estratégias.

Nota-se que em ambas as escolas a grande maioria relatou que não há estratégias preestabelecidas para trabalhar a questão de luto e morte com os alunos. Assim, somente as respostas da minoria dos profissionais de ambas as escolas que responderam que há estratégias preestabelecidas foram categorizadas e serão apresentadas a seguir. A Tabela 1 apresenta a categorização resultante dos relatos dos profissionais da escola particular que disseram que há estratégias preestabelecidas na escola.

Tabela 1. Estratégias preestabelecidas da escola particular para trabalhar o luto com os alunos

\begin{tabular}{lll}
\hline Categorias & $\boldsymbol{f}$ & $\mathbf{\%}$ \\
\hline Estimular a escuta e expressão & 2 & $20,0 \%$ \\
Trabalhar no coletivo & 2 & $20,0 \%$ \\
Trabalhar com a religiosidade & 2 & $20,0 \%$ \\
Propiciar afeto positivo & 2 & $20,0 \%$ \\
Incentivar o conhecimento & 1 & $10,0 \%$ \\
Promover o acolhimento & 1 & $10,0 \%$ \\
\hline Total & 10 & $100 \%$ \\
\hline
\end{tabular}

Nota: $f$ = número de respostas, não de participantes.

Fonte: Dados da própria pesquisa.

Quatro das seis categorias listadas na Tabela 1 se assemelham pela porcentagem de menções. A primeira estratégia utilizada é estimular a criança a expressar e verbalizar suas emoções diante da perda do ente. Foi mencionado também trabalhar com os colegas de sala dando a eles suporte e explicação sobre o ocorrido, proporcionar ao aluno enlutado momentos agradáveis, e ainda, houve relatos sobre a religiosidade como conteúdo de estratégias que a equipe da escola usa para trabalhar o tema morte como, por exemplo, dentro da disciplina de Ensino Religioso. Seguem falas que representam essas categorias.

Conversando inicialmente com a turma a respeito. Fomos ao velório e enterro. Ajudamos com atividade pós luto paralelas, e em todos os momentos houve afeto e cuidado (P18, Professor, 30 anos, Escola Particular).

[...] fazer ela sorrir mais e se misturar com os amigos e ouvi-la (P2, Auxiliar de sala, 19 anos, Escola Particular).

Na escola pública também houve um desencontro de informações, a maioria dos profissionais quando questionados sobre estratégias preestabelecidas relataram que a escola não as possuía, enquanto uma minoria relatou que havia sim tais estratégias. A Tabela 2 traz a categorização dos discursos desta minoria de profissionais da escola pública sobre as estratégias preestabelecidas para trabalhar o luto com o aluno. 
Tabela 2. Estratégias preestabelecidas da escola pública para trabalhar o luto com os alunos

\begin{tabular}{lll}
\hline Categorias & $\boldsymbol{f}$ & $\mathbf{\%}$ \\
\hline Estratégias pedagógicas & 4 & $50,0 \%$ \\
Estimular a escuta e expressão & 1 & $12,5 \%$ \\
Estimular lembranças positivas & 1 & $12,5 \%$ \\
Tratar com naturalidade & 1 & $12,5 \%$ \\
Outros & 1 & $12,5 \%$ \\
\hline Total & 8 & $100 \%$ \\
\hline
\end{tabular}

Nota: $f$ = número de respostas, não de participantes.

Fonte: Dados da própria pesquisa.

A categoria com maior porcentagem de menções $(50,0 \%)$ traz discursos da equipe pedagógica relacionada a um projeto trabalhado com alunos dos anos iniciais do Ensino Fundamental chamado "Amigos do Zippy". Esse programa tem o intuito de propiciar o encorajamento da criança a explorar e analisar alternativas para lidar com as dificuldades. Os professores são capacitados para desenvolver o programa e assim ocupam o lugar de facilitador do desenvolvimento emocional dos alunos (ASSOCIAÇÃO PELA SAÚDE EMOCIONAL DAS CRIANÇAS, 2014). Foi citada ainda a estimulação de diálogos referentes ao tema morte, proporcionando aos alunos um momento para que possam verbalizar o que pensam sobre o assunto. Outra estratégia é sugerir ao aluno que relembre dos momentos felizes ao lado do ente querido e também houve discursos relacionados a não mudar a maneira de tratar a criança após o evento da morte.

Nota-se que houve uma divergência nas falas dos profissionais de ambas as escolas quando se refere à instituição ter estratégias preestabelecidas para trabalhar o luto com os alunos. A maioria mencionou não haver tais estratégias, enquanto uma minoria relatou existir e até citou algumas. Este dado sugere duas hipóteses: a) desconhecimento dos profissionais sobre tais estratégias/ b) divergência na compreensão de termo "estratégias preestabelecidas". Dentre os discursos dessa minoria de profissionais de ambas as escolas, sobre haver estratégias preestabelecidas para trabalhar o tema com os alunos, a única categoria que se repetiu é a que traz menções sobre estimulá-los a falar sobre a morte. Nota-se que a escola pública tem uma preparação para trabalhar o tema com as crianças com o programa "Amigos do Zippy”. Embora os profissionais da desta escola tenham participado da capacitação para utilizar o programa "Amigos do Zippy", a escola não definiu o programa como uma estratégia preestabelecida para trabalhar o luto com os alunos. Relacionado ao Programa Amigos do Zippy, Kovács (2012) constatou que os professores participantes desse programa consideram o tema morte um assunto de sua responsabilidade, o programa os faz refletir sobre o tema e as necessidades encontradas. 


\section{Percepção sobre abordar o Tema Luto com os Alunos}

Os participantes foram questionados sobre sua percepção acerca de trabalhar o tema morte com os alunos, os resultados são apresentados na Tabela 3.

Tabela 3. Percepção dos profissionais da equipe pedagógica de ambas as escolas em trabalhar o tema luto com os alunos de anos iniciais

\begin{tabular}{lcc}
\hline Categorias & $\boldsymbol{f}$ & $\boldsymbol{\%}$ \\
\hline Importante & 15 & $32,6 \%$ \\
Preparação & 9 & $19,5 \%$ \\
Complexo & 8 & $17,3 \%$ \\
Natural & 7 & $15,2 \%$ \\
Bom & 3 & $6,6 \%$ \\
Inapropriado & 2 & $4,4 \%$ \\
Interessante & 2 & $4,4 \%$ \\
\hline Total & 46 & $100 \%$ \\
\hline
\end{tabular}

Nota: $f$ = número de respostas, não de participantes.

Fonte: Dados da própria pesquisa.

Como pode-se perceber na Tabela 3, em sua maioria, as falas tratam da importância de trabalhar o tema com os alunos como processo preparatório para vivências futuras, ajudando-os na superação da perda e na sua compreensão sobre o assunto. Porém, houve profissionais que falaram sobre a complexidade e a dificuldade em trabalhar em sala estas questões, e relatos que acusam preocupação em abordar o tema em função da pouca idade dos alunos. As falas a seguir ilustram as categorias:

É um assunto bastante importante, morte é uma coisa que qualquer pessoa irá passar em algum momento da vida (P5, Auxiliar de sala, 19 anos, Escola Particular).

É um tema forte, e pode causar desconforto na criança se um ente querido morreu [...] (P6, Auxiliar de sala, 18 anos, Escola Particular).

Muitas pessoas acreditam que omitir assuntos como luto e morte das crianças é a melhor saída, pois creem que elas são muito frágeis para passar pelo sofrimento da perda. Por esse motivo, elas acabam escondendo das crianças a morte de algum ente querido. Entretanto, é esse sofrimento que poderá ajudá-las a elaborar seu processo de luto (FERREIRA et al. 2011). O papel que a equipe pedagógica irá desempenhar ajudará o aluno a superar as fases do luto e a compreender melhor o tema. Abordar o assunto de maneira saudável e franca poderá evitar problemas futuros na aprendizagem do aluno (KOVÁCS, 2012; SANTOS, 2013; SILVA, 2011). 


\section{A Superação do Luto na Vida Pessoal dos Profissionais}

A maioria $(87,9 \%)$ dos participantes relataram já terem vivenciado a perda de um ente querido em suas vidas. Separados os resultados por escola, obteve-se na escola pública em $92,3 \%$ o relato de terem esta vivência e $85,0 \%$ na escola privada.

Com o objetivo de verificar o que ajudou os profissionais a superar a perda de um ente querido na sua vida pessoal, na percepção dos próprios, optou-se por questioná-los se já vivenciaram o luto e o que os ajudou a superá-lo. A Tabela 4 apresenta as nove categorias que emergiram dos relatos sobre estas vivências.

Tabela 4. Percepção sobre fatores que ajudara a superar o luto de um ente querido

\begin{tabular}{lcc}
\hline Categorias & $\boldsymbol{f}$ & $\mathbf{\%}$ \\
\hline Recorrer à religião/espiritualidade & 10 & $23,3 \%$ \\
Ser acolhido & 9 & $21,0 \%$ \\
Aceitar a morte & 7 & $16,2 \%$ \\
Receber afeto positivo & 6 & $14,0 \%$ \\
Mudar o foco & 3 & $7,0 \%$ \\
Expressar as emoções & 3 & $7,0 \%$ \\
Reviver lembranças & 2 & $4,6 \%$ \\
Conhecer o tema & 2 & $4,6 \%$ \\
Outros & 1 & $2,3 \%$ \\
Total & 43 & $100 \%$ \\
\hline
\end{tabular}

Nota: $f$ = número de respostas, não de participantes.

Fonte: Dados da própria pesquisa.

Em primeiro lugar com 23,3\% está a categoria que traz menções relacionadas à busca religiosa ou espiritual como auxílio para superar a perda do ente querido. A categoria ser acolhido, que expressa a atenção e o apoio dado por outras pessoas para o enlutado, aparece em segundo lugar com $21,0 \%$ de menções. A terceira categoria mais citada, com 16,2\%, trouxe falas associadas a compreender e aceitar a morte.

[...] o que me ajudou foi a busca espiritual, e tentar equilibrar meu estado de espírito (P7, Auxiliar de sala, 28 anos, Escola Particular).

[...] encarei como uma fase da vida que todos passaremos [...] (P29, Professora, 44 anos, Escola Pública).

[...] melhor coisa era ter alguém por perto juntinho comigo me dando atenção $(P 2$, Auxiliar de sala, 19 anos, Escola Particular).

Os resultados da pesquisa com 32 participantes que passaram por uma experiência de luto realizada por Carvalho e Martins (2006) foram similares aos do presente estudo. Segundo os autores foi possível perceber no relato dos participantes que a fé e as crenças religiosas permitiam uma compreensão da morte como um chamado de Deus, como um evento que

\begin{tabular}{l|c|c|c|c|c|c} 
() Rev. Educ. Perspec. & Viçosa, $M G$ & v.6 & n.2 & p.177-197 & maio/ago. 2017 & eISSN 2178-8359 \\
\hline
\end{tabular}


acontecerá com todos e essa noção dava ao enlutado uma explicação para perda, facilitando a sua aceitação por considerar a morte como parte da obra divina. Para eles, a fé em Deus tornava possível a superação da crise desencadeada pela falta de explicação da perda.

Os participantes foram questionados ainda se a sua experiência pessoal com o luto os ajudou a trabalhar o tema com os alunos. A ocorrência de algum aluno em luto apresentou relação significativa $\left(\chi^{2}=7,02 ; p<0,05\right)$ com a percepção sobre a experiência pessoal ajudar a trabalhar o tema com as crianças, como pode-se observar na Figura 5.

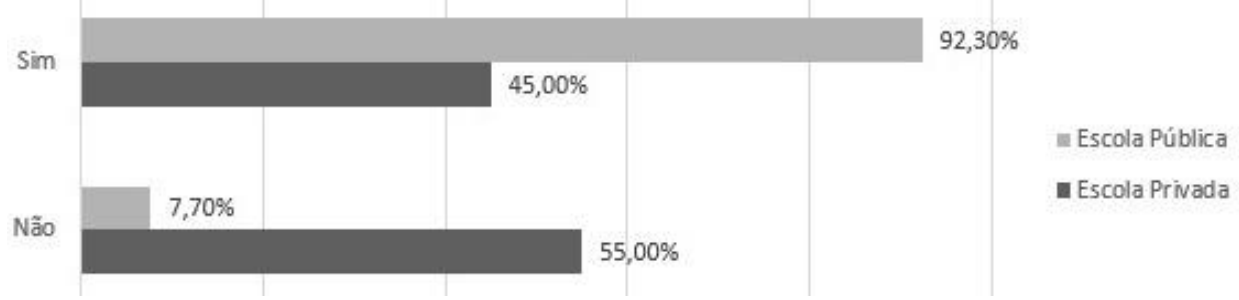

Figura 5. Relação entre a ocorrência de luto discente e sua percepção sobre sua experiência pessoal ajudar a trabalhar o tema com as crianças $\left(\chi^{2}=7,02 ; p<0,05\right)$

Fonte: Dados da própria pesquisa.

Como se pode observar, os profissionais da escola pública, em uma maioria expressiva $(92,3 \%)$, concordam que sua experiência pessoal pode ajudar a trabalhar o tema luto com as crianças. No estudo feito por Kovács (2012) os professores afirmaram que para trabalhar sobre o luto com alunos é preciso que eles próprios tenham uma organização do conhecimento sobre o luto e que a experiência individual seria de grande relevância nesse processo.

\section{Experiência Pessoal com Morte e Luto usada como aspecto auxiliar com Alunos Enlutados}

Os profissionais de ambas as escolas foram questionados se a sua experiência pessoal em relação à morte e ao luto poderia auxiliá-los a trabalhar esses temas com os alunos. As justificativas das respostas afirmativas foram analisadas por sua semelhança e categorizadas, conforme a Tabela 5.

Tabela 5. Estratégias auxiliares para trabalhar os temas luto e morte com os alunos a partir da experiência pessoal dos profissionais

\begin{tabular}{lcc}
\hline Categorias & $\boldsymbol{f}$ & $\boldsymbol{\%}$ \\
\hline Fornecer acolhimento & 11 & $39,3 \%$ \\
Aceitar a morte & 8 & $28,6 \%$ \\
Pela comunicação & 4 & $14,3 \%$ \\
Fornecer afeto positivo & 3 & $10,8 \%$ \\
Mudar o foco & 1 & $3,5 \%$
\end{tabular}

\begin{tabular}{l|l|l|l|l|l|l} 
() Rev. Educ. Perspec. & Viçosa, $M G$ & v.6 & n.2 & p.177-197 & maio/ago. 2017 & eISSN 2178-8359 \\
\hline
\end{tabular}




\begin{tabular}{lcc} 
Outras & 1 & $3,5 \%$ \\
\hline Total & 28 & $100 \%$ \\
\hline
\end{tabular}

Nota: $f$ = número de respostas, não de participante.

Fonte: Dados da própria pesquisa.

\section{Fornecer acolhimento}

A categoria fornecer acolhimento obteve o maior número de menções $(39,3 \%)$. Os discursos elencados nesta categoria sugerem que passar pela experiência de luto ajuda a ouvir e respeitar o aluno e se mostrar presente no momento em que ele precisar.

Me torna uma pessoa mais humana, mais sensível, sabendo me colocar no lugar do outro (P29, Professora, 44 anos, Escola Pública).

\section{Aceitar a morte}

Com $28,6 \%$ de menções, esta categoria traz discursos relacionados a superar a perda aceitando a inevitabilidade da morte. Nas falas que entraram nesta categoria os profissionais relatam que a experiência pessoal de luto faz com que o tema ser abordado de forma mais natural.

[...] tentei passar que todos nós um dia teremos que passar por isso. É o ciclo da vida (P21, Professora, Escola Pública).

\section{Pela comunicação}

Com 14,3\% de menções, os discursos desta categoria sugerem que a experiência do luto pessoal auxilia na hora de dialogar sobre o tema com os alunos, pois é possível compartilhar com eles a sua vivência relacionada à perda.

Com conversa e talvez contando para a criança que também já passei por isso $(P 4$, Auxiliar de sala, 21 anos, Escola Particular).

$\mathrm{Na}$ pesquisa realizada por Kovács (2012) os professores participantes relataram que a experiência pessoal da perda e do luto é uma ferramenta fundamental para abordar o tema com os alunos, mas é necessário ter cuidado ao abordar o assunto levando em conta perguntas e sentimentos das crianças.

No presente estudo, para grande parte dos profissionais, a sua experiência de luto pessoal poderá auxiliar a acolher o aluno, pois ele saberá como o aluno se sente, promovendo empatia, o que ajudaria o profissional a dar o suporte necessário. Esta experiência poderia auxiliar ainda na compreensão do evento morte, ao tratar o assunto como um evento natural e inevitável, e ainda pela comunicação, facilitando diálogos com conteúdos positivos baseados na vivência prévia. Ressalta-se que, embora a maioria dos profissionais tenha relatado que o fator que mais

\begin{tabular}{|c|c|c|c|c|c|c|}
\hline () Rev. Educ. Perspec. & Viçosa, $M G$ & v.6 & n.2 & p.177-197 & maio/ago. 2017 & eISSN 2178-8359 \\
\hline
\end{tabular}


os ajudou nas suas vivências pessoais com o luto foi a religiosidade, ao pontuar como sua vivência auxiliaria sua prática em circunstâncias similares, este fator não foi mencionado.

Quintana et al. (2015) realizaram uma pesquisa na qual constataram, a partir das narrativas dos professores, que a maneira com que cada profissional compreende e vivencia a experiência da perda e do luto reflete na maneira de abordar o tema em sala de aula.

\section{Estratégias de tratamento utilizadas em casos de Aluno Enlutado}

Os profissionais da equipe pedagógica de ambas as escolas foram questionados se durante o período da sua atuação profissional houve algum aluno em luto, e se houve, de que maneira eles tratariam a demanda.

As respostas obtidas dos profissionais da escola particular são apresentadas na Tabela 6.

Tabela 6. Estratégias utilizadas em caso de um aluno enlutado durante a atuação da equipe pedagógica da escola particular

\begin{tabular}{lcc}
\hline Categorias & $\boldsymbol{f}$ & $\mathbf{\%}$ \\
\hline Provendo afeto positivo & 5 & $27,7 \%$ \\
Possibilitando escuta e expressão & 4 & $22,3 \%$ \\
Fornecendo acolhimento & 3 & $16,7 \%$ \\
Trabalhando no coletivo & 3 & $16,7 \%$ \\
Mudando o foco & 2 & $11,1 \%$ \\
Encaminhando a demanda & 1 & $5,5 \%$ \\
\hline Total & 18 & $100 \%$ \\
\hline
\end{tabular}

Nota: $f$ = número de respostas, não de participantes.

Fonte: Dados da própria pesquisa.

\section{Provendo afeto positivo}

Com a maior porcentagem de menções $(27,7 \%)$ está a categoria que trouxe discursos em relação a prover a criança afeto positivo, propiciando momentos, experiências e emoções agradáveis.

Demos a maior atenção possível, carinho e ajuda [...] (P4, Auxiliar de sala, 21 anos, Escola Particular).

\section{Possibilitando escuta e expressão}

Com 22,3\% está a categoria sobre possibilitar ao aluno espaço e tempo para expor suas emoções e sentimentos relacionados à sua perda.

[...] um olhar diferenciado quanto a falas [...] [sic] (P19, Professora, 30 anos, Escola Particular). 


\section{Fornecendo acolhimento}

Esta categoria representa $16,7 \%$ de respostas e refere-se a apoiar o aluno, mostrando-se presente e pronto para auxiliá-lo no que for possível.

Tentando sempre animá-lo falando de coisa positiva (P5, Auxiliar de sala, 19 anos, Escola Particular).

\section{Trabalhando no coletivo}

Também com $16,7 \%$ de respostas está a categoria que remete a estratégias que consideram não apenas o aluno enlutado, mas toda a turma, preparando os demais alunos para receber o aluno enlutado.

[...] abordando o assunto com a turma e os alunos com cautela, para que não tivesse constrangimento. E não magoar o sentimento do aluno (P15, Professora, 33 anos, Escola Particular).

A categorização emergente das respostas dos profissionais da equipe pedagógica da escola particular foca principalmente no aluno enlutado, porém, não deixando de trabalhar também o contexto ao qual ele está inserido, que são seus colegas de classe.

Na Tabela 7 é apresentada a categorização emergente dos discursos dos profissionais da equipe pedagógica da escola pública.

Tabela 7. Estratégias utilizadas em caso de um aluno enlutado durante a atuação da equipe pedagógica da escola pública

\begin{tabular}{llc}
\hline Categorias & $\boldsymbol{f}$ & $\mathbf{\%}$ \\
\hline Possibilitando escuta e expressão & 8 & $33,2 \%$ \\
Fornecendo acolhimento & 8 & $33,2 \%$ \\
Trabalhando no coletivo & 3 & $12,6 \%$ \\
Provendo afeto positivo & 2 & $8,4 \%$ \\
Encaminhando a demanda & 1 & $4,2 \%$ \\
Contato com a família & 1 & $4,2 \%$ \\
Outros & 1 & $4,2 \%$ \\
\hline Total & 24 & $100 \%$ \\
\hline
\end{tabular}

Nota: $f$ = número de respostas, não de participantes.

Fonte: dados da própria pesquisa.

\section{Possibilitando escuta e expressão e fornecendo acolhimento}

Ambas as categorias que estão em primeiro lugar com 33,2\% de menções fazem referência à postura de deixar o aluno livre para se expressar, sem julgá-lo, proporcionando à criança momentos para expor suas crenças e auxiliando-a no que for possível.

\begin{tabular}{l|c|c|c|c|c|c} 
() Rev. Educ. Perspec. & Viçosa, $M G$ & v.6 & n.2 & p.177-197 & maio/ago. 2017 & eISSN 2178-8359 \\
\hline
\end{tabular}


Respeitamos o tempo da criança em relação as suas reações diante do luto [...] ( $P 25$, Professora, 39 anos, Escola Pública).

[...] Apoio emocional ao aluno (P28, Professora, 23 anos, Escola Pública).

\section{Trabalhando no coletivo}

Trabalhar o luto em sua coletividade significa não focar em quem está vivenciando o luto, e sim em todos os que estão a sua volta. Na percepção dos profissionais da escola pública, trabalhar o luto coletivo é necessário, dando aos colegas de classe do aluno enlutado suporte e explicação sobre o acontecido. Essa categoria ficou em terceiro lugar com 12,6\%.

Falamos com os alunos de forma clara e sensível sobre o acontecimento [...] (P29,

Professora, 44 anos, Escola Pública).

\section{Provendo afeto positivo}

Em terceiro lugar com $8,4 \%$ de menções, esta categoria diz respeito à postura do profissional de propiciar experiências prazerosas e agradáveis.

\section{[...] demonstrando carinho [...] (P21, Professora, Escola Pública).}

De certa maneira, as categorias se repetiram em ambas as escolas alterando apenas a sua colocação relacionada à porcentagem de menções. Quanto às categorias diferentes, na escola particular há falas relacionadas a mudar o foco da vivência de luto para outra situação ou pessoa significativa de seu convívio, enquanto a escola pública traz uma categoria relacionada ao contato com os pais do aluno enlutado.

As respostas ao questionamento "Durante o seu período de atuação do profissional houve algum aluno em luto pela perda de um ente querido?", fizeram com que emergissem, em ambas as escolas, quatro principais categorias: provendo afeto positivo, possibilitando a escuta e expressão, fornecendo acolhimento e trabalhando no coletivo. Ou seja, no geral, os profissionais das duas escolas trazem discursos relacionados a proporcionar ao aluno um momento qualitativo para que ele possa expressar o que está sentindo e pensando.

Houve também discursos relacionados a dar à criança a atenção necessária para a superação do luto proporcionando experiências positivas e agradáveis e em conversar com os colegas de sala sobre o momento que o aluno vivencia. Kappel (2013) relata que a dor e a saudade durante o período de luto são inevitáveis. Assim, se faz necessário que a escola e os educadores busquem alternativas para esclarecer à criança que a morte é um evento natural, estimulando-a a falar sobre suas emoções, de modo a dar o acompanhamento adequado, respeitando e observando as reações da criança frente ao fato. As escolas podem enfatizar a importância de se trabalhar com

\begin{tabular}{l|c|c|c|c|c|c} 
(C) Rev. Educ. Perspec. & Viçosa, $M G$ & v.6 & n.2 & p.177-197 & maio/ago. 2017 & eISSN 2178-8359 \\
\hline
\end{tabular}


as crianças enlutadas em grupos por meio de diálogos, jogos, brincadeiras, entre outras atividades planejadas (SILVA, 2011).

\section{CONSIDERAÇÕES FINAIS}

Este trabalho teve por objetivo analisar a percepção de equipes pedagógicas sobre o luto de alunos dos anos iniciais, sobre as possibilidades de acolhimento e intervenção desses profissionais frente a esta demanda e possíveis relações com a vivência de luto dos próprios profissionais. Por meio da análise dos dados pôde-se chegar a algumas reflexões a respeito da percepção da equipe pedagógica acerca do luto de alunos e intervenções possíveis.

Percebeu-se que os profissionais, durante o processo de luto infantil, consideram importante propiciar escuta e expressão, acolher, proporcionar à criança momentos agradáveis e de emoções positivas, além de conversar com o restante da turma sobre o tema para que ocorra o acolhimento também por parte destes, e para que a turma entenda o que está acontecendo com o colega de classe. Estas estratégias são comumente colocadas em prática pelos profissionais para se trabalhar com alunos enlutados.

Os profissionais da escola pública estavam em uma faixa etária mais alta, tinham mais tempo de atuação na área e uma experiência maior em relação à ocorrência de alunos enlutados. $\mathrm{Na}$ escola privada os profissionais viveram menos a experiência de luto de aluno e a maioria relatou não ter pensado em trabalhar o tema em sala com seus alunos.

A pesquisa trouxe resultados acerca da percepção dos profissionais sobre as dificuldades e responsabilidades da equipe frente ao aluno enlutado. Percebeu-se que os profissionais veem a necessidade e a importância de trabalhar o tema luto com os alunos como maneira de preparálos para uma possível perda. Entretanto, alguns relatam uma preocupação com o tema, por conta de sua complexidade.

Quanto à vivência dos profissionais das equipes em relação ao luto dos alunos e as suas experiências pessoais, percebeu-se nos relatos a ideia de que viver a experiência do luto pode ajudar na compreensão da situação em que o aluno está passando, possibilitando que os profissionais abordem o tema de forma natural, compartilhando sua vivência da perda, mostrando que a morte é inevitável e que é possível superá-la. Porém, convém ressaltar que os resultados que se referem à percepção trazem relações feitas pelos próprios participantes, estas relações perpassam sua subjetividade e refletem uma interação entre compreensões do senso comum e perspectivas de sua prática.

Relacionando os dados de acordo com os tipos de escola, tem-se na escola pública uma maioria expressiva que acreditava que sua experiência pessoal poderia ajudar a trabalhar o tema luto 
com as crianças. Quando se trata de estratégias preestabelecidas, tanto na escola pública quanto na particular, notou-se uma incongruência de relatos dos profissionais. Em ambas as escolas houve uma maioria que disse não haver tais estratégias, enquanto uma minoria discordou, alegando que havia estratégias preestabelecidas para trabalhar tais questões.

Compreender o aluno que vivência a morte de um ente querido poderá ajudá-lo na elaboração do luto. Pôde-se perceber com esta pesquisa que a maioria dos profissionais acredita que trabalhar o tema com as crianças seja relevante e que, apesar da falta de estratégias préestabelecidas pelas escolas, eles improvisam cursos de ação para não deixar de trabalhar o tema com os alunos ou acolher um aluno enlutado.

Como limitação deste estudo aponta-se o número pequeno de participantes da amostra, em função deste fator as relações encontradas nos resultados precisam ser entendidas como exploratórias e geradoras de hipóteses que poderão mover outros estudos, mais específicos e direcionados. Ainda, a divisão não igualitária de quantidade de participantes professores em cada escola, com a presença de um número considerável de auxiliares de sala apenas na escola privada, fragilizou os dados comparativos entre os tipos de escola. Assim, é importante lembrar do caráter exploratório do estudo, sem pretensões de generalização da amostra.

\section{REFERÊNCIAS}

ANTON, Márcia Camaratta; FAVERO, Eveline. Morte repentina de genitores e luto infantil: uma revisão da literatura em periódicos científicos brasileiros. Interação em Psicologia, v. 15 n. 1, Porto Alegre, 2011.

\section{ASSOCIAÇÃO PELA SAÚDE EMOCIONAL DAS CRIANÇAS. Programa Amigos do} Zippy. 2014. Disponível em: <goo.gl/qkadMq.> Acesso em: 17 set. 2017.

BROMBERG, Maria Helena Pereira Franco. A psicoterapia em situações de perdas e luto. 2.ed. São Paulo: Psy, 1998.

GADDIS, Gary; GADDIS, Monica. Introduction to Biostatistics: Part 5, Statistical Inference Techniques for Hypothesis Testing With Nonparametric Data. Annals of Emergency Medicine, v. 19, n. 9, 1990.

CARVALHO, Cátia Daniela Rodrigues; MARTINS, José. Luto e Religiosidade. Monografia (Licenciatura em Psicologia) Instituto Superior da Maia, Portugal, 2006.

DAL-FARRA, Rossano André; LOPES, Paulo Tadeu Campos. Métodos mistos de pesquisa em educação: pressupostos teóricos. Nuances: Estudos sobre Educação, v. 24, n. 3, p. 67-80, 2013.

\begin{tabular}{l|c|c|c|c|c|c} 
() Rev. Educ. Perspec. & Viçosa, $M G$ & v.6 & n.2 & p.177-197 & maio/ago. 2017 & eISSN 2178-8359 \\
\hline
\end{tabular}


FERREIRA, J. B. A.; SILVA, S. A.; OLIVEIRA, Patricia Alves; CARVALHO, E. L. L. Perda e luto na infância: o desvínculo e sua consequência na formação do psiquismo. [S.1.]:

Faculdades Integradas de Ourinhos - FIO/FEMM, 2011

FRANCO, Maria Helena Pereira; MAZORRA, Luciana. Criança e luto: vivências fantasmáticas diante da morte do genitor. Estudos de Psicologia, v. 24, n. 4, 2007.

FUJISAKA, Ana Paula; KOVÁCS, Maria Julia. Vivência de luto em adultos que perderam a mãe na infância. 2011. Dissertação (Mestrado em Psicologia) - Universidade de São Paulo, Programa de Pós-graduação em Desenvolvimento Humano, São Paulo, 2011.

GIACOIA, Júnior Oswaldo. A visão da morte ao longo do tempo. Revista Medicina, v. 38, n. $1,2005$.

JARAMILLO, Isa Fonnegra de. Morrer bem. 1. ed. São Paulo: Editora Planeta, 2006.

KAPPEL, Aline dos Santos. Luto Infantil: um estudo através das representações. Revista Maiêutica, v. 1, n. 1, 2013.

KOVÁCS, Maria. Julia. Educadores e a morte. Revista Semestral da Associação Brasileira de Psicologia Escolar e Educacional, v. 16, 2012.

MAZORRA, Luciana; TINOCO, Valéria. Luto na infância: intervenções psicológicas em diferentes contextos. São Paulo: Livro Pleno, 2005.

MOURA, Cristina Marcos de. Uma avaliação da vivência do luto conforme o modo de morte. 2006. Dissertação (Mestrado em Psicologia) - Universidade de Brasília, Brasília, 2006.

PAIVA, Lucélia Elizabeth. A arte de fala da morte para crianças. São Paulo: Ideias \& Letras, 2011.

QUINTANA, Alberto Manuel; FRONZA, Leila Portela; WEISSHEIMER, Taiane Klein dos Santos; BARBIERI, Ângela. O tema da morte na escola: possibilidades de reflexão. Universidade Federal de Santa Maria. Rio Grande do Sul, 2015.

RUIZ-OLABUÉNAGA, Jose Ignacio. Metodologia de la investigación cualitativa. 5. ed. Bilbao, España: Universidad de Deusto, 2012.

SANTOS, Ariane Cavalcanti dos. O Luto no ambiente escolar da educação infantil. 2013. Monografia (Graduação em Licenciatura Plena de Pedagogia Series Iniciais e Gestão Escolar) Faculdade de Educação de Porto Velho, Porto Velho, 2013.

SILVA, Raquel Vasconcelos. O papel da escola e da família no resgate da autoestima pós luto. 2011 Monografia (Licenciatura em Pedagogia) - Universidade de Brasília, Faculdade de Educação, Brasília, 2011.

\begin{tabular}{l|c|c|c|c|c|c|} 
(C) Rev. Educ. Perspec. & Viçosa, $M G$ & v.6 & n.2 & p.177-197 & maio/ago. 2017 & eISSN 2178-8359 \\
\hline
\end{tabular}


SILVA, Camila Caetano da; WENDLING, Maria Isabel. 2010. Luto infantil: o trabalho dos professores com alunos enlutados. Monografia (Graduação em Psicologia) - Faculdades Integradas de Taquara, Taquara, 2010.

TADA, Iracema Neno Cecilio; KOVÁCS, Maria Júlia. Conversando Sobre a Morte e o Morrer na Área da Deficiência. Psicologia, Ciência e Profissão, v. 27, n. 1, Brasília, 2007.

TORRES, Nione. Luto: a dor que não se perde com o tempo (...ou se perde?). In:

ENCONTRO DE PSICOTERAPIA E MEDICINA COMPORTAMENTAL, 18.: 2009:

[Anais do...]. Campinas, SP: ABPMC, 2009.

\section{Sobre as Autoras}

${ }^{\text {i } M a i a r a}$ Cardoso dos Santos Souza - Psicóloga pela Faculdade Metropolitana de Guaramirim - Uniasselvi. E-mail: maiaracdss@gmail.com

${ }^{i i}$ Renata Lissa Zwolinski - Psicóloga pela Faculdade Metropolitana de Guaramirim Uniasselvi. E-mail: zwolinski57@gmail.com

iii Rosina Forteski Glidden - Psicóloga pela Faculdade Metropolitana de Guaramirim Uniasselvi. Mestre em Educação pela Universidade Federal do Paraná. E-mail:

rsforteski@gmail.com 